\title{
Respiratory Protective Equipment, Mask Use, and Respiratory Outcomes among World Trade Center Rescue and Recovery Workers
}

\author{
Vinicius C. Antao, MD, MSc, PhD, ${ }^{1 *}$ L. Lászlo Pallos, PhD, PE, ${ }^{1}$ Youn K. Shim, PhD, MSHyg, $^{1}$ \\ James H. Sapp II, MS, ${ }^{1}$ Robert M. Brackbill, PhD, MPH, ${ }^{2}$ James E. Cone, MD, MPH, ${ }^{2}$ \\ Steven D. Stellman, $\mathrm{PhD}, \mathrm{MPH}^{2,3}$ and Mark R. Farfel, $\mathrm{SCD}^{2}$
}

\begin{abstract}
Background Serious respiratory illnesses have been reported among rescue/recovery workers (RRW) following the World Trade Center (WTC) attacks.

Methods We studied RRW enrolled in the WTC Health Registry to assess the effects of different respiratory protection equipment (RPE) types on respiratory outcomes, such as recurrent respiratory symptoms and diseases possibly associated with 9/11 exposures. We performed descriptive and multivariate analyses adjusting for demographics and exposure variables.

Results A total of 9,296 RRW met inclusion criteria. The strongest predictors of using adequate RPE were being affiliated with construction, utilities or environmental remediation organizations and having received RPE training. Workers who used respirators were less likely to report adverse respiratory outcomes compared to those who reported no/lower levels of respiratory protection.

Conclusions Level of respiratory protection was associated with the odds of reporting respiratory symptoms and diseases. Training, selection, fit testing, and consistent use of RPE should be emphasized among emergency responders. Am. J. Ind. Med. 54:897-905, 2011. (c) 2011 Wiley Periodicals, Inc.
\end{abstract}

KEY WORDS: respiratory symptoms; respiratory protective equipment; asthma; COPD; disasters; disaster response; World Trade Center

\footnotetext{
${ }^{1}$ Division of Health Studies, Agency for Toxic Substances and Disease Registries, Atlanta, Georgia

${ }^{2}$ New York City Department of Health and Mental Hygiene, Long Island City, New York

${ }^{3}$ Department of Epidemiology, Mailman School of Public Health, Columbia University, New York, New York

Contract grant sponsor: $\mathrm{CDC} / \mathrm{NIOSH}$.

Contract grant sponsor: ATSDR.

Contract grant sponsor:NYC DOHMH

Disclaimer: This study was supported by Cooperative Agreement U50/ATU272750 from the Agency for Toxic Substances and Disease Registry (ATSDR), Centers for Disease Control and Prevention (CDC), which included support from the National Center for Environmental Health and by Cooperative Agreement U50/OH009739 from the National Institute for Occupational Safety and Health (NIOSH) and the New York City Department of Health and Mental Hygiene. The findings and conclusions in this report are those of the authors and do not necessarily represent the views of the ATSDR or CDC/NIOSH.

Disclosure Statement: The authors declare they have no competing financial interests.

${ }^{\star}$ Correspondence to: Vinicius C. Antao, MD, MSc, PhD, 4770 Buford Highway NE, MS

F-57 Atlanta, GA 30341.E-mail: vantao@cdc.gov
}

Accepted 25 August 2011

DOl 10.1002/ajim.21009. Published online 19 September 2011 in Wiley Online Library (wileyonlinelibrary.com).

\section{INTRODUCTION}

Unprecedented respiratory hazards were present in the wake of the terrorist attacks on the World Trade Center (WTC) in New York City on September 11, 2001 [Prezant et al., 2008]. The spectrum of WTC-related respiratory disease includes upper respiratory disease (the newly recognized "WTC Cough Syndrome" [Prezant et al., 2002] sinus problems, nose irritation, and postnasal irritation [Brackbill et al., 2006]), and lower airway disease (reactive airway dysfunction syndrome (RADS)/irritant-induced asthma [Centers for Disease Control and Prevention 2002; Reibman et al., 2005], and pulmonary function abnormalities [Prezant et al., 2002; Salzman et al., 2004; Skloot et al., 2004; Herbert et al., 2006]). It also includes some rare parenchymal diseases, such as acute eosinophilic 
pneumonia [Rom et al., 2002], sarcoid-like granulomatous pulmonary disease [Izbicki et al., 2007], granulomatous pneumonitis [Safirstein et al., 2003], and bronchiolitis obliterans [Mann et al., 2005].

A variety of respiratory effects have been reported among WTC workers who carried out many different tasks. Among ironworkers at the WTC site, cough was the most common symptom, followed by shortness of breath and wheezing [Skloot et al., 2004]. New York City police officers experienced an increase in the prevalence of respiratory symptoms over 19 months of followup, except for cough, which remained steady at $43.5 \%$, reflecting two trends, resolution of early onset cough and emergence of delayed-onset cough, counterbalancing each other [Buyantseva et al., 2007]. Elevated rates of respiratory outcomes were also shown for New York City Transit [Tapp et al., 2005] and Department of Sanitation workers [Tao et al., 2007] and among participants of the WTC Worker and Volunteer Medical Screening Program [Herbert et al., 2006]. Among NYC firefighters cough and sore throat markedly declined over 4 years after the WTC disaster, but rates remained much higher than before 9/11 [Webber et al., 2009]. New York State employees who responded to the WTC disaster had higher rates of persistent lower respiratory symptoms 5 years after 9/11, compared to non-exposed controls [Mauer et al., 2010].

It is well established that in emergency situations, respiratory protective equipment (RPE) may be used to protect individuals from exposure to dusts, fumes, smoke, gases, and vapors, which may be associated with some of the respiratory diseases described above [Harber et al., 1996]. Wheeler et al. studied 25,748 WTC rescue and recovery workers (RRW) (police, firefighters, emergency medical services (EMS) workers, construction or engineering personnel, and sanitation workers) with no prior history of asthma. They were asked, "On [9/11, and other time periods after 9/11] did you wear a mask all of the time, most of the time, some of the time, or not at all?" The term "mask" was inclusive of many types of facial coverings, ranging from surgical or nuisance dust masks not certified for ability to prevent inhalation of airborne particles to true respiratory protection. Although the study was unable to differentiate between use of masks versus true respiratory protection, Wheeler et al. [2007] found that longer delays in the initial use of masks or respirators among workers who arrived at the site on $9 / 11$ and worked throughout the entire clean-up phase were associated with an increased risk of newly diagnosed asthma.

While the report by Wheeler et al. is the largest study to date to suggest the effectiveness of RPE in protecting disaster responders against respiratory illness, its assessment was based solely on the initial 2003-2004 WTC
Health Registry survey which did not distinguish between masks not intended for protecting against inhalation of aerosols and respirators. As noted in the conclusions of their study, and incorporated into the first WTC Health Registry follow-up survey, effective use of RPE requires selection of the appropriate protective device, training in its use, "personalization" of the equipment to fit the individual, and consistency of use in hazardous conditions. The objective of the present report is to describe patterns of use of specific types of masks and respirators, training in respirator usage, and respirator fit testing and their impact on respiratory outcomes in the subset of RRW who worked on the WTC debris pile and participated in the Registry's follow-up survey.

\section{METHODS}

The WTC Health Registry is a collaborative effort between the Agency for Toxic Substances and Disease Registry (ATSDR), the National Institute for Occupational Safety and Health (NIOSH), and the New York City Department of Health and Mental Hygiene. It is the largest effort in the United States to monitor health after a disaster. Details of the Registry population have been described elsewhere [Farfel et al., 2008]. In brief, the Registry contains data on 68,444 adults, of whom 30,665 reported performing rescue/recovery work. Between September, 2003 and November, 2004, enrollees completed a baseline computer-assisted telephone interview $(95 \%)$ or in-person $(5 \%)$ interview (Wave 1, W1) that provided data on demographics and self-reported exposures and health outcomes. A follow-up survey (Wave 2, W2), conducted between November, 2006 and December, 2007, updated enrollees' health status and gathered additional data on exposures. A total of 9,296 RRW who worked for at least one shift on the WTC debris pile completed both W1 and W2 surveys and provided data on RPE and mask use relevant to this study. The Centers for Disease Control and Prevention and New York City Department of Health and Mental Hygiene institutional review boards approved the Registry protocols. A Federal Certificate of Confidentiality was obtained, as was oral informed consent.

\section{RPE and Mask Use}

The W2 Survey contained detailed questions about RPE and mask use, including illustrations depicting full facepiece and half-facepiece elastomeric respirators (type 1 and 2, respectively), disposable filtering facepiece respirators (type 3) and devices such as surgical or nuisance dust masks (type 4). These illustrations are reproduced in Figure 1. In addition, there were questions about which type of device was used the most in three different time 

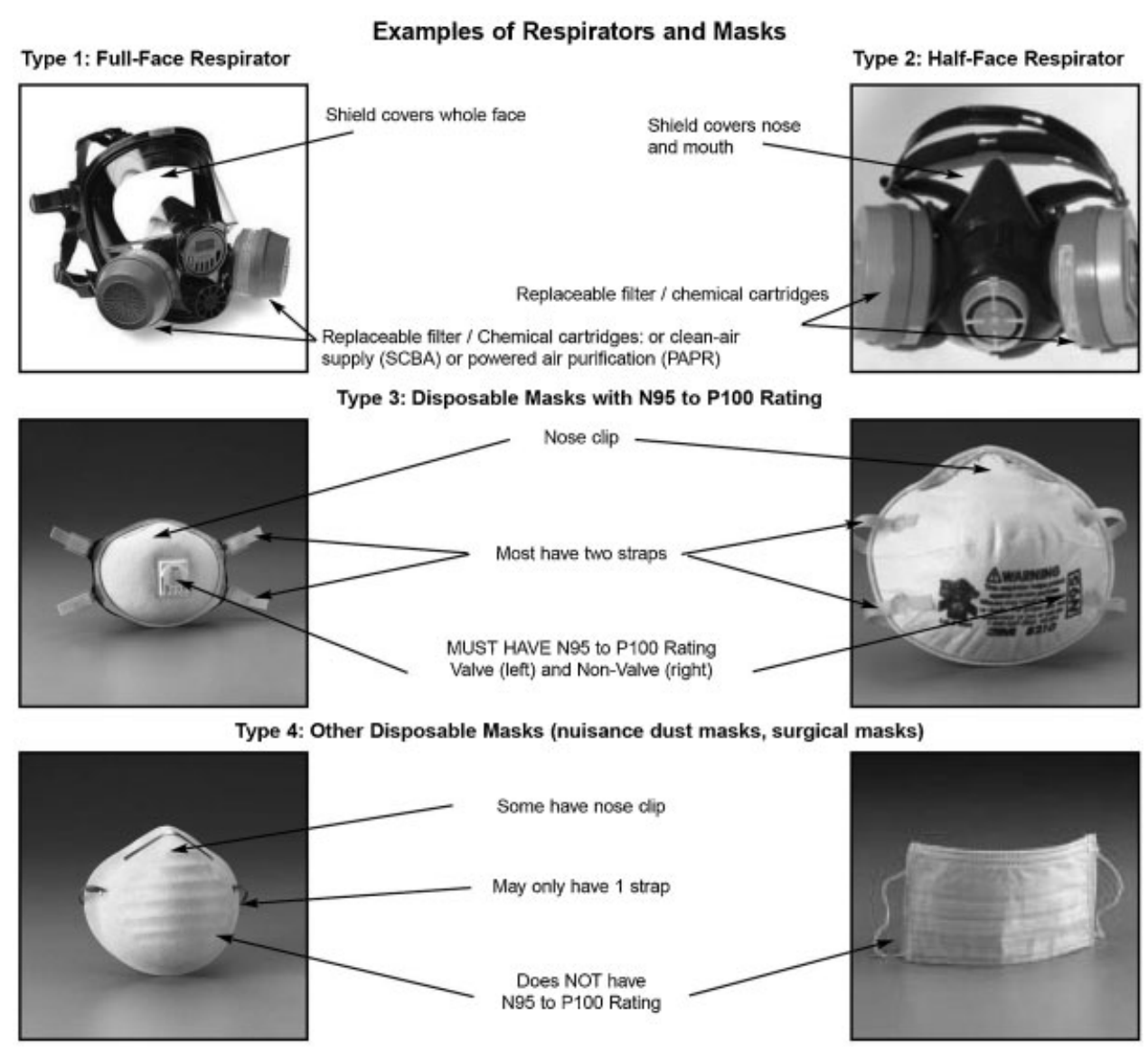

FIGURE 1. Types of RPE and masks as depicted in the World Trade Center Health Registry Wave 2 questionnaire.

periods $(9 / 11 / 01 ; 9 / 12-12 / 31 / 01$; and from $1 / 1 / 02$ onward) and training in the use of RPE received before or during WTC-related work. For type 1 and 2 respirator users, there were further questions about RPE fit testing and maintenance.

For analysis, we determined a single level of respiratory protection for each person by choosing the minimum level of protection (i.e., type 1, 2, 3, 4, or none) specified across all periods worked. For example, if a worker had responded to the question "On [time period], which type of mask or respirator did you wear the most?" as follows: "type 4" for $9 / 11 / 01$, "type 3 " for $9 / 12-12 / 31 / 01$, and "type 2" for 1/1/02 onward, the overall protection level for that worker would be set to "type 4". Those workers who did not use respiratory protection (type 1-4) most of the time in at least one period they worked were categorized overall as "No protection".

Proper fitting, respirator cleaning, and changing cartridges were treated as dichotomous variables (all or most of the time versus some or none of the time), and included as covariates during the three time periods described above.

\section{Health Outcomes}

Outcomes of interest were respiratory symptoms first occurring or worsening after $9 / 11$ and present at W2 and respiratory diseases first diagnosed after $9 / 11$ and present at W2. Lower respiratory symptoms included shortness of breath, wheezing, and persistent chronic cough. Upper respiratory symptoms included throat irritation, sinus problems or nose/post nasal irritation. Asthma was defined as a self-reported first lifetime physician diagnosis of asthma or RADS, and chronic obstructive pulmonary disease (COPD) as a physician diagnosis of chronic bronchitis or emphysema, all after 9/11.

\section{Statistical Analysis}

We performed descriptive statistics and multivariate logistic regression analyses. To examine predictors of RPE or mask use for each time period, covariates in the models were sex, age on 9/11, education (less than high school, high school, some college, or college or more), smoking status (ever vs. never smoking), RPE training (yes vs. no) 
and worksite affiliation. To investigate the association between respiratory protection levels and the likelihood of reporting adverse health outcomes, we adjusted for sex, age, education, smoking status, worksite affiliation, total number of days worked, and when the work started. We also adjusted for exposure to the cloud of dust/debris that was generated by the collapse of the WTC towers, and which has been shown in numerous studies to be associated with respiratory outcomes. Dust cloud exposure was classified as none, some, or intense, as described by Brackbill et al. [2009]. All analyses were performed using SAS version 9.1 (SAS Institute Inc, Cary, NC).

\section{RESULTS}

A total of 9,296 RRW at the WTC site met the inclusion criteria for this study. Table I shows demographic and exposure characteristics. The group's median age on

TABLE I. Demographic and Exposure Characteristics of 9,296 RRWs and Volunteers Enrolled in the WTC Health Registry*

\begin{tabular}{|c|c|c|}
\hline Characteristic & $\mathbf{N}$ & $\%$ \\
\hline Age (years, mean \pm SD) & $45.4 \pm 8.8$ & - \\
\hline Sex (male) & 8,586 & 92.4 \\
\hline \multicolumn{3}{|l|}{ Education $^{\mathrm{a}}$} \\
\hline$<$ Highschool & 284 & 3.1 \\
\hline High school & 2,262 & 24.5 \\
\hline Some college & 3,367 & 36.5 \\
\hline College + & 3,325 & 36.0 \\
\hline Ever smoking $^{\mathrm{a}}$ & 3,943 & 42.6 \\
\hline Days worked at WTC site (mean \pm SD) & $50.9 \pm 60.4$ & - \\
\hline \multicolumn{3}{|l|}{ Dust cloud exposure on $9 / 11^{\mathrm{a}}$} \\
\hline None & 5,307 & 60.3 \\
\hline Some & 845 & 9.6 \\
\hline Intense & 2,648 & 30.1 \\
\hline \multicolumn{3}{|l|}{ Affiliation $^{\mathrm{a}}$} \\
\hline Fire and rescue & 2,818 & 30.4 \\
\hline EMS $^{\mathrm{b}}$ and medical, medical examiner & 458 & 4.9 \\
\hline Law enforcement and military & 2,114 & 22.8 \\
\hline Construction, utilities, remediation & 1,242 & 13.4 \\
\hline Sanitation & 446 & 4.8 \\
\hline Public agency, not already specified & 1,115 & 12.0 \\
\hline Volunteers and miscellaneous & 1,086 & 11.7 \\
\hline \multicolumn{3}{|l|}{ Training on RPE } \\
\hline Before $9 / 11$ only & 2,375 & 26.4 \\
\hline During 9/11 work only & 1,425 & 15.8 \\
\hline Before and during $9 / 11$ work & 1,981 & 22.0 \\
\hline Notraining & 3,227 & 35.8 \\
\hline
\end{tabular}

${ }^{*}$ RRWs and volunteers included in the analysis have worked for at least one shift on the WTC debris pile and participated in the Registry's Wave 1 and Wave 2 surveys.

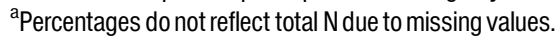

bEMS, emergency medical services.
9/11 was 39 years (mean 45.4 years, range $16-78$ years). The great majority of subjects was male and had at least high school education. Almost half $(42.4 \%)$ of the subjects had ever smoked cigarettes and 39.7\% reported some or intense dust cloud exposure on $9 / 11$ [Brackbill et al., 2009]. Over half of the subjects were affiliated with firefighting and rescue services (30.4\%) or law enforcement/military $(22.8 \%)$ followed by construction/utilities/remediation (13.4\%), public administration (12.0\%), medical/EMS (4.9\%), and sanitation (4.8\%). Volunteers accounted for $11.7 \%$.

Variability in participation rates by worker category was observed, with the lowest response rate $(62.09 \%)$ among construction/utility workers, and the highest $(83.25 \%)$ among fire and rescue workers. Intermediate levels of participation were demonstrated by EMS/Medical/ Morgue workers (80.07\%), Public Administration workers (77.00\%), Police and Law Enforcement workers (74.73\%), Volunteers (70.13\%) and Sanitation workers (64.18\%). However, there was little difference between participants and non-participants of $\mathrm{W} 2$ by exposure measures including dust cloud, when they arrived, or number of days worked (data not shown).

RPE use by time period worked on the WTC pile is shown in Table II. Less than $20 \%$ of workers reported using type 1,2, or 3 respirators on $9 / 11$ and half of the workers wore no respirator or mask at all on that date. Approximately one-third of subjects reported using only disposable surgical masks most of the time (Type 4) during the first two periods of response (i.e., 9/11/01 and 9/ 12-12/31/01), whereas half-face respirators (Type 2) were the most common RPE type worn after 1/1/02.

A total of 2,340 out of 5,737 RRW (40.8\%) who wore type 1 or 2 respirators on or after $9 / 11$ reported having had a fit-test. In addition, 2,843/5,418 (52.5\%) reported that RPE fitted well all or most of the time. The proportion of those who performed RPE maintenance, all or most of the time, was as follows: 1,809/5,307 (34.1\%) cleaned the respirator before use and 1,238/5,227 (23.7\%) replaced cartridges. Thirty-six percent $(3,227 / 9,008)$ of RRW had no training in RPE use either before or during WTC related work, whereas $22 \%$ had training both before and during WTC work (Table I). Changes in denominators are due to non-response.

Overall, the strongest predictors of use of respiratory protection (types 1-3) were having received training in the use of RPE and being affiliated with construction, utilities, or remediation organizations (Table III). On 9/11, being affiliated with fire and rescue, EMS, law enforcement and military, or sanitation work was negatively associated with use of respiratory protection. This association reversed in the period 9/12-12/31/01 for those affiliated with law enforcement and military and in the period after 1/1/02 for fire and rescue and EMS workers. 
TABLE II. RPE or Mask Use (Most or all of the Time) Among 9,296 RRWs and Volunteers Enrolled in the WTC Health Registry*

\begin{tabular}{|c|c|c|c|c|c|c|c|c|}
\hline \multirow{2}{*}{$\frac{\text { Period }}{\text { RPE or mask type }^{a}}$} & \multicolumn{2}{|c|}{$\begin{array}{c}9 / 11 / 01 \\
(N=6,573)\end{array}$} & \multicolumn{2}{|c|}{$\begin{array}{c}9 / 12-12 / 31 / 01 \\
(N=8,675)\end{array}$} & \multicolumn{2}{|c|}{$\begin{array}{l}\text { 1/1/02 and after } \\
(N=5,766)\end{array}$} & \multicolumn{2}{|c|}{$\begin{array}{c}\text { Minimum protection } \\
\text { level across all periods }(\mathrm{N}=\mathbf{9 , 1 2 9})\end{array}$} \\
\hline & n & $\%$ & n & $\%$ & n & $\%$ & n & $\%$ \\
\hline 1 & 140 & 2.1 & 241 & 2.8 & 298 & 5.2 & 213 & 2.3 \\
\hline 2 & 689 & 10.5 & 3,072 & 35.4 & 2,660 & 46.1 & 1,634 & 17.9 \\
\hline 3 & 398 & 6.1 & 1,170 & 13.5 & 508 & 8.8 & 732 & 8.0 \\
\hline 4 & 2,086 & 31.7 & 2,931 & 33.8 & 701 & 12.2 & 2,429 & 26.6 \\
\hline None & 3,260 & 49.6 & 1,261 & 14.5 & 1,599 & 27.7 & 4,121 & 45.1 \\
\hline
\end{tabular}

*RRWs and volunteers included in the analysis have worked for at least one shift on the WTC debris pile and participated in the Registry's Wave 1 and Wave 2 surveys. Type 1: full-face respirators; Type 2: half-face respirators; Type 3: filtering facepiece respirators with N95 to P100 rating; type 4: other disposable masks.

Table IV shows the prevalence of self-reported post-9/ 11 respiratory diseases and recurrent new or worsening post-9/11 respiratory symptoms at W2. The most common recurrent lower respiratory symptom was shortness of breath $(29.6 \%)$, followed by wheezing and chronic cough. Upper respiratory symptoms were reported by $71.6 \%$ of
RRW. The prevalence of new onset asthma/RADS was $15.6 \%$, and that of COPD, $9.7 \%$.

RRWs who reported wearing type 1 respirators were only half as likely $(\mathrm{OR}=0.52)$ to report new or recurrent chronic cough at W2 compared to those who reported no respiratory protection (Table Va). That likelihood was

TABLE III. Predictors of Use of Respiratory Protection (Type1, 2, or 3 Respirator), byTime Period, Among 9,296 RRWs and Volunteers Enrolled in the WTC Health Registry*

\begin{tabular}{|c|c|c|c|c|c|c|}
\hline \multirow[b]{3}{*}{ Variable } & \multicolumn{6}{|c|}{ Number of positives and odds ratio (95\% confidence interval) $)^{a}$ for use of type 1,2, or 3 RPE $^{b}$} \\
\hline & \multicolumn{2}{|c|}{$9 / 11 / 01$} & \multicolumn{2}{|c|}{$9 / 12-12 / 31 / 01$} & \multicolumn{2}{|c|}{$1 / 1 / 02$ and after } \\
\hline & $+/$ Total & OR (95\% CI) & $+/$ Total & OR (95\% CI) & $+/$ Total & OR (95\% CI) \\
\hline \multicolumn{7}{|l|}{ Age (16-34 years-old) } \\
\hline 35-39years-old & $715 / 1,963$ & $0.96(0.84-1.09)$ & $1,081 / 1,997$ & $1.02(0.90-1.15)$ & $1,453 / 1,927$ & $1.11(0.96-1.28)$ \\
\hline 40-45 years-old & $785 / 2,129$ & $0.95(0.84-1.08)$ & $1,157 / 2,179$ & $0.98(0.87-1.11)$ & $1,532 / 2,096$ & $0.94(0.82-1.07)$ \\
\hline$>46$ years-old & $986 / 2,070$ & $1.33(1.17-1.51)$ & $1,162 / 2,133$ & $1.03(0.91-1.17)$ & $1,498 / 2,011$ & $1.00(0.87-1.15)$ \\
\hline Male sex (female) & $3,078 / 7,890$ & $0.84(0.71-1.00)$ & $4,324 / 8,047$ & $1.11(0.94-1.32)$ & $5,732 / 7,713$ & $1.36(1.13-1.63)$ \\
\hline \multicolumn{7}{|l|}{ Education (<high school) } \\
\hline Highschool & $776 / 2,060$ & $1.09(0.82-1.44)$ & $1,073 / 2,103$ & $0.99(0.75-1.31)$ & $1,446 / 2,003$ & $1.25(0.93-1.68)$ \\
\hline Some college & $1,168 / 3,115$ & $1.28(0.97-1.69)$ & $1,682 / 3,168$ & $1.15(0.87-1.52)$ & $2,256 / 3,047$ & $1.37(1.02-1.85)$ \\
\hline College + & $1,325 / 3,121$ & $1.39(1.05-1.83)$ & $1,771 / 3,177$ & $1.24(0.94-1.64)$ & $2,297 / 3,068$ & $1.48(1.10-1.99)$ \\
\hline Never smoking (ever smoking) & $1,913 / 4,937$ & $1.07(0.97-1.17)$ & $2,746 / 5,002$ & $1.17(1.07-1.29)$ & $3,583 / 4,826$ & $1.01(0.91-1.12)$ \\
\hline Any $\mathrm{RPE}^{\mathrm{b}}$ training (No RPE training) & $2,498 / 5,519$ & $1.82(1.64-2.01)$ & $3,511 / 5,648$ & $2.64(2.39-2.90)$ & $4,335 / 5,429$ & $2.19(1.97-2.43)$ \\
\hline \multicolumn{7}{|l|}{ Organization (volunteers and miscellaneous) } \\
\hline Fire and rescue & $819 / 2,616$ & $0.39(0.34-0.46)$ & $1,312 / 2,669$ & $0.86(0.74-1.01)$ & $2,069 / 2,578$ & $1.64(1.38-1.96)$ \\
\hline EMS $^{\mathrm{C}}$ and medical, medical examiner & $161 / 434$ & $0.49(0.38-0.62)$ & $255 / 444$ & $1.17(0.92-1.47)$ & $328 / 422$ & $1.38(1.05-1.81)$ \\
\hline Law enforcement and military & $532 / 1,977$ & $0.38(0.32-0.45)$ & $1,019 / 1,989$ & $1.25(1.07-1.47)$ & $1,292 / 1,934$ & $1.00(0.84-1.19)$ \\
\hline Construction, utilities, remediation & $679 / 1,120$ & $1.41(1.17-1.69)$ & $773 / 1,144$ & $1.96(1.62-2.36)$ & $844 / 1,110$ & $1.27(1.03-1.56)$ \\
\hline Sanitation & $126 / 398$ & $0.52(0.40-0.67)$ & $157 / 405$ & $0.85(0.67-1.10)$ & $235 / 371$ & $0.94(0.72-1.22)$ \\
\hline Public agency, notalready specified & $562 / 1,032$ & $1.02(0.85-1.22)$ & $673 / 1,058$ & $1.59(1.32-1.91)$ & $750 / 992$ & $1.27(1.03-1.55)$ \\
\hline
\end{tabular}

\footnotetext{
*RRWs and volunteers included in the analysis have worked for at least one shift on the WTC debris pile and participated in the Registry's Wave 1 and Wave 2 surveys.

${ }^{a}$ Adjusted for sex, age at 9/11, education, smoking status, RPE training, and organization (worksite affiliation). Reference categories for each variable in the multivariate logistic regression model are in parenthesis and statistically significant results in bold.

${ }^{\mathrm{b}} \mathrm{RPE}$, respiratory protective equipment.

${ }^{\mathrm{C}}$ EMS, emergency medical services.
} 
TABLE IV. Prevalence of Self-Reported Post-9/11, Respiratory Symptoms and Respiratory Diseases Present at W2 Among 9,296 RRWs and Volunteers Enrolled in the WTC Health Registry*

\begin{tabular}{|c|c|c|}
\hline Symptom/disease & $\mathbf{N}^{\mathbf{a}}$ & $\%$ \\
\hline Shortness of breath & $2,571 / 8,672$ & 29.6 \\
\hline Wheezing & $2,052 / 8,780$ & 23.4 \\
\hline Chronic cough & $1,453 / 9,248$ & 15.7 \\
\hline Upper respiratory symptoms & $6,466 / 9,030$ & 71.6 \\
\hline Asthma/RADS ${ }^{b}$ & $1,315 / 8,411$ & 15.6 \\
\hline COPD & $855 / 8,775$ & 9.7 \\
\hline
\end{tabular}

${ }^{*}$ RRWs and volunteers included in the analysis have worked for at least one shift on the WTC debris pile and participated in the Registry's Wave 1 and Wave 2 surveys. ${ }^{a}$ Changes in denominators are due to non-response.

${ }^{\mathrm{b}} \mathrm{RADS}$, reactive airways dysfunction syndrome.

$70 \%(\mathrm{OR}=0.70)$ for upper respiratory symptoms. Although not statistically significant, odds ratios for other respiratory symptoms were also protective (OR range: 0.74-0.76) in this group. In addition, RRW who wore type 2 respirators were approximately $70 \%$ (OR range:
$0.69-0.74)$ as likely to repeatedly report all respiratory symptoms compared to those who reported no respiratory protection. The odds increased to around 80\% (OR range: $0.70-0.90$ ) when the comparison was made with those who reported type 3 use (only upper respiratory symptoms was not statistically significant). The comparison between type 4 masks and no respiratory protection was statistically significant for chronic cough $(\mathrm{OR}=0.81$, $\mathrm{CI}=0.75-0.95)$ and upper respiratory symptoms $(\mathrm{OR}=$ $0.85 \mathrm{CI}=0.75-0.97)$. For asthma/RADS, this association was significant for type 2 respirators and type 4 masks versus no protection, whereas for COPD it was only significant for type 2 respirators versus no protection.

Additional analysis of the differences between device types and their association with adverse respiratory outcomes suggest that there is a difference for some outcomes when type 4 devices are used as the comparison (Table $\mathrm{Vb}$ ). Type 2 and type 3 devices had statistically significant odds ratios for shortness of breath $(\mathrm{OR}=0.71$ and 0.81 , respectively) and wheezing $(\mathrm{OR}=0.71$ and 0.77 , respectively). Type 2 was also more protective against $\mathrm{COPD}(\mathrm{OR}=0.72)$ compared to type 4 .

TABLE V. Post-9/11Respiratory Symptoms or Diseases Present at W2 in Relation to (a) Device Type Versus no Protection and (b) Device Type Versus the Next Higher Level of Respiratory Protection, Among 9,296 RRWs and Volunteers Enrolled in the WTC Health Registry ${ }^{\mathrm{a}}$

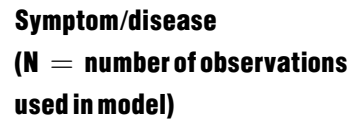

Odds ratio $(95 \% \text { confidence interval })^{b}$ for each respiratory condition

\begin{tabular}{|c|c|c|c|}
\hline $\begin{array}{c}\text { Type } 1 \mathrm{device}^{\mathrm{c}} \\
\text { versus no protection }\end{array}$ & $\begin{array}{c}\text { Type } 2 \text { device }^{c} \\
\text { versus no protection }\end{array}$ & $\begin{array}{c}\text { Type } 3 \text { device }^{c} \\
\text { versus no protection }\end{array}$ & $\begin{array}{c}\text { Type } 4 \text { device } \\
\text { versus no protection }\end{array}$ \\
\hline
\end{tabular}

$\begin{array}{lll}0.74(0.50-1.10) & \mathbf{0 . 6 9}(\mathbf{0 . 5 8}-\mathbf{0 . 8 2}) & \mathbf{0 . 7 9 ( 0 . 6 4 - 0 . 9 7 )} \\ 0.76(0.50-1.18) & \mathbf{0 . 6 9 ( 0 . 5 7 - 0 . 8 2 )} & \mathbf{0 . 7 4 ( 0 . 5 9 - 0 . 9 3 )} \\ \mathbf{0 . 5 2}(\mathbf{0 . 3 0}-\mathbf{0 . 9 0}) & \mathbf{0 . 7 3 ( 0 . 6 0 - 0 . 8 9 )} & \mathbf{0 . 7 0 ( 0 . 5 4 - 0 . 9 0 )} \\ \mathbf{0 . 7 0}(\mathbf{0 . 5 0}-\mathbf{0 . 9 9 )} & \mathbf{0 . 7 4}(\mathbf{0 . 6 3}-\mathbf{0 . 8 6 )} & 0.90(0.73-1.09) \\ 0.64(0.37-1.11) & 0.81(0.65-1.00) & 0.82(0.63-1.07) \\ 0.97(0.56-1.69) & \mathbf{0 . 7 0}(\mathbf{0 . 5 4}-\mathbf{0 . 9 0} & 1.10(0.83-1.47)\end{array}$

$0.98(0.86-1.11)$

$0.96(0.84-1.10)$

$0.81(0.70-0.95)$

$0.85(0.75-0.97)$

$0.79(0.68-0.93)$

$0.97(0.81-1.16)$

\begin{tabular}{|c|c|c|c|}
\hline \multirow{2}{*}{$\begin{array}{l}\text { Symptom/disease } \\
\text { (N = number of observations } \\
\text { used in model) }\end{array}$} & \multicolumn{3}{|c|}{ Odds ratio ( $95 \%$ confidence interval) for each respiratory condition } \\
\hline & $\begin{array}{c}\text { Type } 1 \mathrm{device}^{\mathrm{c}} \\
\text { versus type } 4 \text { device }^{\mathrm{c}}\end{array}$ & 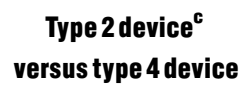 & $\begin{array}{c}\text { Type } 3 \text { device }^{c} \\
\text { versus type } 4 \text { device }\end{array}$ \\
\hline \multicolumn{4}{|l|}{ (b) } \\
\hline Shortness of breath $(\mathrm{N}=7,522)$ & $0.76(0.51-1.14)$ & $0.71(0.59-0.85)$ & $0.81(0.65-1.00)$ \\
\hline Wheezing $(\mathrm{N}=7,607)$ & $0.79(0.51-1.23)$ & $0.71(0.59-0.87)$ & $0.77(0.60-0.97)$ \\
\hline Chronic cough $(\mathrm{N}=8,017)$ & $0.60(0.40-1.10)$ & $0.90(0.70-1.10)$ & $0.90(0.70-1.10)$ \\
\hline Upper respiratory symptoms ( $\mathrm{N}=7,831)$ & $0.82(0.58-1.17)$ & $0.87(0.74-1.02)$ & $1.05(0.86-1.29)$ \\
\hline Asthma/RADS ${ }^{\mathrm{a}}(\mathrm{N}=7,312)$ & $0.80(0.46-1.41)$ & $1.02(0.81-1.28)$ & $1.04(0.78-1.37)$ \\
\hline $\mathrm{COPD}(\mathrm{N}=7,658)$ & $1.00(0.57-1.24)$ & $0.72(0.54-0.95)$ & $1.14(0.84-1.54)$ \\
\hline
\end{tabular}

Type 1: Full-face respirators; Type 2: Half-face respirators; Type 3: Filtering facepiece respirators with N95 to P100 rating; Type 4: 0ther disposable mas.

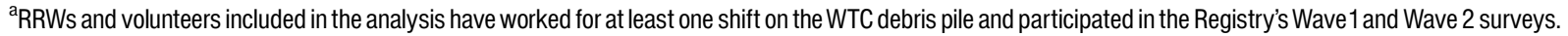

${ }^{\mathrm{b}}$ Adjusted for sex, age, education, smoking status, dust cloud exposure, organization (worksite affiliation), total number of days worked, and first day worked. Statistically significant results from the multivariate logistic regression are in bold.

${ }^{\mathrm{C}} \mathrm{RADS}$, reactive airways dysfunction syndrome. 


\section{DISCUSSION}

This study demonstrates a clear association between the use of RPE and respiratory health outcomes after a major disaster in which workers were subjected to unexpected, intense, and prolonged pulmonary insults. It is the first study to show the impact of different levels of respiratory protection on health outcomes in a large sample of RRW. In the field of occupational health, few researchers have looked at the association of different types of RPE and specific health outcomes. Small studies of epoxy resin workers [Grammer et al., 2002], law enforcers involved in methamphetamine lab investigations [Witter et al., 2007], and aluminum potroom workers [Kongerud and Rambjor, 1991] have not been able to definitively demonstrate that the use of respirators was protective against respiratory symptoms, occupational asthma, or changes in peak expiratory flow rates. Our data show that, in general, the protection level was associated with the odds of developing respiratory symptoms and diseases. In addition, our evaluation demonstrated that receiving training was one of the most important factors in predicting RPE use among RRWs.

Our data demonstrated that during the first day of response, half of the workers wore no respiratory protection at all and approximately one-third wore unrated disposable masks only. This improved over time, with $50 \%$ of responders wearing type 1 or 2 respirators most of the time after $1 / 1 / 02$, although $28 \%$ of the workers reported no respiratory protection after 1/1/02 (twice as prevalent as the previous period). Feldman et al. [2004] reported a similar trend among Fire Department of New York (FDNY) firefighters, with 57\% using type 2 respirators during the second week of response, although only $53 \%$ of those used them most of their work time. Likewise, Mauer et al. [2007] reported that among New York State personnel who responded to the WTC disaster, use of disposable dust masks decreased over time, while the use of respirators increased. Lack of use of respirators during the initial response has also been reported among other worker categories, such as ironworkers [Skloot et al., 2004] and police officers [Buyantseva et al., 2007].

Another important issue faced by RRWs at the WTC site was the need for proper RPE training and fit-testing. Approximately one-third of RRW reported no RPE training at all, and less than half of RRW who wore type 1 or 2 respirators reported they had been fit-tested. Specifically, $27 \%$ of RRW affiliated with fire and rescue did not report RPE training either before or during WTC-related work. The same was true for EMS (21\%), and law enforcement (55\%). Proper RPE maintenance was also deficient: only one-third reportedly cleaned the respirator before use and roughly $20 \%$ replaced cartridges. A report from the
RAND Institute states that in some cases, cartridges were discarded after $<2 \mathrm{hr}$ of use, while in other cases RRWs would work for the entire week on one cartridge [RAND Science and Policy Institute, 2002].

Our data show that having received any RPE training was one of the strongest predictors of RPE use during the disaster response. Previously reported barriers to using RPE, especially in the early days after $9 / 11$, included difficulty in communicating with peers, the burden of breathing through RPE, lack of appropriate components to match specific types of respirators, and in the case of law enforcers, the simple lack of RPE, since "most lawenforcement agencies did not allocate enough funding to stockpile RPE", according to a report from the RAND Institute (RAND Science and Policy Institute). Nevertheless, the FDNY [Mauer et al., 2007], other city agencies, the private sector, and unions went through a massive effort to address the safety of their workers within the first week after the attack and during several months afterwards. These efforts included WTC site orientation and training, distribution of respirators as they became available, and manual seal fit tests on firefighters during respirator distribution, conducted by OSHA personnel [Spadafora, 2002].

To ensure that we were capturing health outcomes related to WTC exposures in this analysis, our case definitions for reported respiratory symptoms and diseases included the concept of onset or worsening after 9/11 and required the presence of symptoms at least 30 days before the W2 interview, which occurred 5-6 years after the disaster. The finding of elevated rates of respiratory diseases and recurrent respiratory symptoms in this study are consistent with previous reports from the WTC Health Registry and medical surveillance and monitoring programs that followed this population. Among RRW enrolled in the WTC Health Registry, W1 data showed that almost $80 \%$ of RRW who worked on the debris pile reported at least one new or worsening respiratory symptom after 9/11 [Farfel et al., 2008]; from W1 and W2 data, the incidence of asthma 5-6 years after 9/11 among RRW was $12.2 \%$ (95\% CI (11.8-12.7\%)), which is at least two times higher than national estimates [Brackbill et al., 2009].

A strength of this study is the ability to examine the impact of different types of respiratory protection or mask use in a large cohort of RRWs with massive exposure to respiratory hazards. The introduction into the W2 survey of questions on respirator or mask type, training, and fit testing has resulted in a substantial extension of the earlier findings of the importance of respirator or mask usage and timing [Wheeler et al., 2007]. Our analyses take into account previously recognized confounders, such as start date of work at the WTC site, duration of exposure, intensity of dust cloud exposure, smoking status, and 
demographic characteristics. We clearly demonstrate that type 2 respirators have a protective effect on almost all respiratory outcomes included in this analysis, with the exception of asthma (barely statistically significant). In addition, it appears that the odds are associated with level of protection for most respiratory outcomes, although most results for type 1 respirators were not statistically significant, perhaps due to small numbers in that category (only up to $5 \%$ of RRW reported type 1 use). Moreover, our results help to highlight the relative lack of protective effects of non-rated surgical masks (type 4 devices) in such scenarios of exposure. Except for chronic cough, upper respiratory symptoms, and asthma, there was no statistically significant difference between using surgical masks and not using RPE, with regard to protection against respiratory outcomes. Nevertheless, in the event of an unanticipated disaster of this magnitude, some protection is preferable to none at all, but use of low-protection devices should be regarded as a last resort, and disaster planning should focus on providing equipment with higher levels of effectiveness as demonstrated in this study.

Our findings are consistent with those of Skloot et al. [2004] who showed better lung function (decreased large airways resistance as demonstrated via impulse oscillometry) in ironworkers who wore a respirator with canister during the WTC disaster response compared to those who did not wear a respirator. In a different setting, Carrasco et al. [2006] showed that provision of health information to workers engaged in the clean-up of the Prestige oil spill in Asturias and Cantabria was associated with a greater use of individual protective devices and lower frequency of acute health problems, including respiratory outcomes. In contrast, a study of NYC firefighters who responded to 9/11 events did not find a significant association between the use of respirators and respiratory outcomes (symptoms, pulmonary function, or airway hyperreactivity) [Prezant et al., 2002]. Banauch et al. [2006] did not find a protective effect of mask use frequency on pulmonary function among firefighters after the disaster. However, these two FDNY studies summarized the use of respirators over the entire response period, potentially missing the effect of timing of RPE use.

This study is potentially subject to several limitations, common to analyses that use self-reported questionnaire data. First, self-selection bias may affect our sample. Workers who developed respiratory symptoms and diseases after 9/11 may have been more prone to enroll in the WTC registry than asymptomatic workers. In addition, we were not able to verify reported conditions using medical records, which would have been useful to rule out overreporting of respiratory outcomes by study participants. Nevertheless, we do not expect that differences between respondents and non-respondents and misclassification of disease status would have an influence on the likelihood of using RPE, and therefore it is unlikely that these limitations affect our main findings. Moreover, non-respondents to W2 (among the pile workers) did not differ from the respondents in terms of demographics and exposures. In addition, there is the possibility that current symptoms could influence the reporting of past use of RPE, which would result in overestimate of the protective effect. This could arise if participants "explained" their persistent or new onset symptoms as being partly due to not having been properly trained or equipped with RPE. Recall bias is always a possibility, especially when questionnaires are applied over 5 years after the event of interest. In an attempt to account for this factor, we cross-checked responses on W1 and W2 for consistency. Ascertainment of RPE use may have been problematic for several reasons. The accuracy of reporting RPE use over a day (e.g., 9/11) is likely higher than that of reporting over a period (e.g., 9/12-12/31/01) because one may ignore intermittent use. However, the question on RPE use does ask "what type mask or respirator did you wear the most?", which would theoretically reflect RPE use over a day as well as over a period. Misclassification of overall respiratory protection level may have occurred since we chose the minimum level of protection over the entire period worked for each individual, instead of period specific RPE use. This more conservative approach is based on the belief that even brief periods without respiratory protection may be associated with some respiratory health outcomes. Further analysis demonstrated that $<2 \%$ of the RRW who had worn type 1,2 , or 3 devices in the first two periods (supposedly the ones with more intense exposure) were classified as "no protection" when they could have been deemed as "partially protected". This categorization resulted from the lack of respiratory protection use in the last period. Nevertheless, no substantial differences in the results of Table Va,b were detected when these potentially "misclassified" individuals were removed from analysis (data not shown). Finally, exposures are likely to have differed among workers affiliated with different RRW organizations. In an attempt to minimize this heterogeneity, we included "organization" as a covariate in the multivariate models.

In conclusion, we demonstrate clear associations between the use and level of respiratory protection and reductions in adverse respiratory health outcomes. As expected, respirators proved to have a substantial protective effect, whereas other, non-respirator disposable masks did not confer similar levels of protection. The benefits of appropriate respiratory protection, including training and fit-testing, as well as enforcement of consistent use in emergency situations with significant exposures to dusts, fumes, and/or smoke cannot be overemphasized. 


\section{REFERENCES}

Banauch GI, Hall C, Weiden M, Cohen HW, Aldrich TK, Christodoulou V, Arcentales N, Kelly KJ, Prezant DJ. 2006. Pulmonary function after exposure to the World Trade Center collapse in the New York City Fire Department. Am J Respir Crit Care Med 174:312-319.

Brackbill RM, Thorpe LE, DiGrande L, Perrin M, Sapp JH, Wu D, Campolucci S, Walker DJ, Cone J, Pulliam P, Thalji L, Farfel MR, Thomas P. 2006. Surveillance for World Trade Center disaster health effects among survivors of collapsed and damaged buildings. MMWR Surveill Summ 55:1-18.

Brackbill RM, Hadler JL, DiGrande L, Ekenga CC, Farfel MR, Friedman S, Perlman SE, Stellman SD, Walker DJ, Wu D, Yu S, Thorpe LE. 2009. Asthma and posttraumatic stress symptoms 5 to 6 years following exposure to the World Trade Center terrorist attack. JAMA 302:502-516.

Buyantseva LV, Tulchinsky M, Kapalka GM, Chinchilli VM, Qian Z, Gillio R, Roberts A, Bascom R. 2007. Evolution of lower respiratory symptoms in New York police officers after 9/11: A prospective longitudinal study. J Occup Environ Med 49:310-317.

Carrasco JM, Lope V, Perez-Gomez B, Aragones N, Suarez B, LopezAbente G, Rodriguez-Artalejo F, Pollan M. 2006. Association between health information, use of protective devices and occurrence of acute health problems in the Prestige oil spill clean-up in Asturias and Cantabria (Spain): A cross-sectional study. BMC Public Health 6:1-9.

Centers for Disease Control and Prevention. 2002. Self-reported increase in asthma severity after the September 11 attacks on the World Trade Center-Manhattaan, New York, 2001. MMWR Morb Mortal Wkly Rep 51:781-784.

Farfel M, DiGrande L, Brackbill R, Prann A, Cone J, Friedman S, Walker DJ, Pezeshki G, Thomas P, Galea S, Williamson D, Frieden TR, Thorpe L. 2008. An overview of 9/11 experiences and respiratory and mental health conditions among World Trade Center Health Registry enrollees. J Urban Health 85:880-909.

Feldman DM, Baron SL, Bernard BP, Lushniak BD, Banauch G, Arcentales N, Kelly KJ, Prezant DJ. 2004. Symptoms, respirator use, and pulmonary function changes among New York City firefighters responding to the World Trade Center disaster. Chest 125:1256-1264.

Grammer LC, Harris KE, Yarnold PR. 2002. Effect of respiratory protective devices on development of antibody and occupational asthma to an acid anhydride. Chest 121:1317-1322.

Harber P, Barnhart S, Boehlecke BA, Beckett WS, Gerrity T, McDiarmid MA, Nardbell E, Repsher L, Brousseau L, Hodous TK, Utell MJ. 1996. Respiratory protection guidelines. Am J Respir Crit Care Med 154:1153-1165.

Herbert R, Moline J, Skloot G, Metzger K, Baron S, Luft B, Markowitz S, Udasin I, Harrison D, Stein D, Todd A, Enright P, Stellman JM, Landrigan PJ, Levin SM. 2006. The World Trade Center disaster and the health of workers: Five-year assessment of a unique medical screening program. Environ Health Perspect 114:1853-1858.

Izbicki G, Chavko R, Banauch GI, Weiden MD, Berger KI, Aldrich TK, Hall C, Kelly KJ, Prezant DJ. 2007. World Trade Center "sarcoid-like" granulomatous pulmonary disease in New York City Fire Department rescue workers. Chest 131:1414-1423.

Kongerud J, Rambjor O. 1991. The influence of the helmet respirator on peak flow rate in aluminum potroom. Am Ind Hyg Assoc J 52: 243-248.

Mann JM, Sha KK, Kline G, Breuer FU, Miller A. 2005. World Trade Center dyspnea: Bronchiolitis obliterans with functional improvement: A case report. Am J Ind Med 48:225-229.
Mauer MP, Cummings KR, Carlson GA. 2007. Health effects in New York State personnel who responded to the World Trade Center disaster. J Occup Environ Med 49:1197-1205.

Mauer MP, Cummings KR, Hoen R. 2010. Long-term respiratory symptoms in World Trade Center responders. Occup Med (Lond) 60:145-151.

Prezant DJ, Weiden M, Banauch GI, McGuinness G, Rom WN, Aldrich TK, Kelly KJ. 2002. Cough and bronchial responsiveness in firefighters at the World Trade Center site. N Engl J Med 347:806815

Prezant DJ, Levin S, Kelly KJ, Aldrich TK. 2008. Upper and lower respiratory diseases after occupational and environmental disasters. Mt Sinai J Med 75:89-100.

RAND Science and Policy Institute. 2002. Protecting emergency responders: Lessons learned from terrorist attacks. Santa Monica, CA: RAND Science and Policy Institute. Available at http://www.rand. org/publications/CF/CF176.

Reibman J, Lin S, Hwang SA, Gulati M, Bowers JA, Rogers L, Berger KI, Hoerning A, Gomez M, Fitzgerald EF. 2005. The World Trade Center residents' respiratory health study: New-onset respiratory symptoms and pulmonary function. Environ Health Perspect 113:406-411.

Rom WN, Weiden M, Garcia R, Yie TA, Vathesatogkit P, Tse DB, McGuinness G, Roggli V, Prezant D. 2002. Acute eosinophilic pneumonia in a New York City firefighter exposed to World Trade Center dust. Am J Respir Crit Care Med 166:797-800.

Safirstein BH, Klukowicz A, Miller R, Teirstein A. 2003. Granulomatous pneumonitis following exposure to the World Trade Center collapse. Chest 123:301-304.

Salzman SH, Moosavy FM, Miskoff JA, Friedmann P, Fried G, Rosen MJ. 2004. Early respiratory abnormalities in emergency services police officers at the World Trade Center site. J Occup Environ Med 46:113-122.

Skloot G, Goldman M, Fischler D, Goldman C, Schechter C, Levin S, Teirstein A. 2004. Respiratory symptoms and physiologic assessment of ironworkers at the World Trade Center disaster site. Chest 125:1248-1255.

Spadafora R. 2002. Firefighter safety and health issues at the World Trade Center site. Am J Ind Med 42:532-538.

Tao XG, Massa J, Ashwell L, Davis K, Schwab M, Geyh A. 2007. The world trade center clean up and recovery worker cohort study: Respiratory health amongst cleanup workers approximately 20 months after initial exposure at the disaster site. J Occup Environ Med 49:1063-1072.

Tapp LC, Baron S, Bernard B, Driscoll R, Mueller C, Wallingford K. 2005. Physical and mental health symptoms among NYC transit workers seven and one-half months after the WTC attacks. Am J Ind Med 47:475-483.

Webber MP, Gustave J, Lee R, Niles JK, Kelly K, Cohen HW, Prezant DJ. 2009. Trends in respiratory symptoms of firefighters exposed to the world trade center disaster: 2001-2005. Environ Health Perspect 117:975-980.

Wheeler K, McKelvey W, Thorpe L, Perrin M, Cone J, Kass D, Farfel M, Thomas P, Brackbill R. 2007. Asthma diagnosed after 11 September 2001 among rescue and recovery workers: Findings from the World Trade Center Health Registry. Environ Health Perspect 115:1584-1590.

Witter RZ, Martyny JW, Mueller K, Gottschall B, Newman LS 2007. Symptoms experienced by law enforcement personnel during methamphetamine lab investigations. J Occup Environ Hyg 4:895902. 